\title{
Global financial integration and monetary policy spillovers
}

\author{
Dongwon Lee* \\ Department of Economics, University of California, Riverside, CA 92521, United States
}

This version: November 24, 2020

\begin{abstract}
This paper uses de facto financial market integration estimated based on an international CAPM for the purpose of re-examining the validity of an open-economy policy trilemma in the recent period of globalization. We find that unlike the policy constraints of emerging market economies, which are consistent with the trilemma predictions, either a flexible exchange rate regime or segmentation from global finance alone does not seem to provide as much insulation against foreign interest rate shocks in advanced economies.
\end{abstract}

Keywords: Dilemma hypothesis; Global financial integration; Interest rate pass-through; Monetary independence; Open-economy policy trilemma

JEL classification: $\mathrm{F} 32 ; \mathrm{F} 33 ; \mathrm{F} 42$

*E-mail address: dwlee@ucr.edu; Tel.: +1-951-827-1505. 


\section{Introduction}

The recent financial globalization has rekindled debate on the validity of the openeconomy policy trilemma. ${ }^{1}$ While the empirical literature generally supports that some monetary discretion can be retained with a flexible exchange rate regime (Frankel et al., 2004; Shambaugh, 2004; Obstfeld et al., 2005; Klein and Shambaugh, 2015; Aizenman et al., 2016; and Han and Wei, 2018), Rey (2015) argued that emerging market economies (EMEs) face a dilemma in the presence of a global financial cycle in that the type of exchange rate regime is irrelevant.

To contribute to the ongoing debate, this paper estimates a de facto measure of financial market integration in the recent globalization period and applies it to re-examine the trilemma hypothesis, which has typically been tested using de jure capital controls. Unlike de jure indicators, the estimated de facto measures provide relatively higher-frequency information about market integration with considerable time variation. Our approach is similar to that of Bekaert and Mehl (2019) but different in the following aspects for better identification.

First, the sample in this paper includes EMEs as well as advanced economics (AEs) so that the hypothesis testing can rely on a distribution of integration covering a wider range of values. Second, the quarterly data provide sufficient time-series information to consider finer exchange rate regimes beyond a simple binary classification while allowing for a continuous integration variable. Third, the model explicitly controls for other determinants of monetary policy such as local and global market conditions to assess the robustness of policy spillovers.

Our results indicate that unlike EMEs' policy constraints in the recent decades, which are closely in line with the trilemma predictions, either a flexible exchange rate regime or segmentation from global finance alone does not seem to provide as much insulation against

\footnotetext{
${ }^{1}$ The trilemma refers to the tradeoffs that a small open economy faces among the choices of monetary policy autonomy, exchange rate stability, and financial openness (Mundell, 1963).
} 
foreign interest rate shocks in AEs. Moreover, in contrast to Bekaert and Mehl (2019), who provided historical evidence based on the century-long data, the effects of recent financial market integration on interest rate pass-through in AEs appear to be more pronounced under floating regimes than under pegging regimes.

\section{Empirical methodology and data}

\subsection{Empirical methodology}

To measure global financial integration, we estimate the following two-factor international CAPM in each country $i$ over non-overlapping quarterly windows using the daily data:

$$
S_{i, t}=c_{i}+\beta_{i, t}^{g l o} F_{t}^{g l o, \backslash i}+\beta_{i, t}^{r e g} F_{t}^{r e g, \backslash i}+\epsilon_{i, t}
$$

where $S_{i, t}$ is the excess return on the local stock index in U.S. dollars (over the U.S. 3-month Tbill rate); $c_{i}$ is a country-specific constant; $F_{t}^{g l o, \backslash i}$ and $F_{t}^{r e g, \backslash i}$ are value-weighted excess returns (excluding country $i$ 's own returns) from the global and regional markets, respectively; and $\epsilon_{i, t}$ is the idiosyncratic shock of market $i{ }^{2}$ Including both global and regional factors is necessary to provide maximum flexibility in the model, as the market integration process may not proceed smoothly (Bekaert et al., 2009). ${ }^{3}$

The estimated quarterly global betas $\left(\hat{\beta}_{i, t}^{\text {glo }}\right)$ serve as indicators of global financial integration. The integration estimates in the full sample have a median of 0.54 (with standard

\footnotetext{
${ }^{2}$ The global factor is calculated using the daily equity index returns of the 20 AEs, including the United States. For regional factor calculation, we consider three regions: Asia-Pacific (Australia, China, Hong Kong, India, Indonesia, Japan, Korea, Malaysia, New Zealand, Pakistan, the Philippines, Singapore, and Thailand); Europe, Middle East, and Africa (Austria, Belgium, Czech Republic, Denmark, Egypt, Finland, France, Germany, Hungary, Ireland, Israel, Italy, the Netherlands, Norway, Poland, Portugal, Russia, South Africa, Spain, Sweden, Switzerland, Turkey, and the United Kingdom); and Americas (Brazil, Canada, Chile, Colombia, Mexico, Peru, and the United States).

${ }^{3}$ The regional returns are orthogonalized with respect to the global returns before entering the regression.
} 
deviation of 0.28), and the corresponding values for AEs and EMEs are $0.62(0.22)$ and 0.44 (0.30), respectively. According to the time series plots in Fig. 1, the degree of market integration in both AEs and EMEs has shown a moderate upward trend over the last two decades, with a declining gap between the two groups in the recent past.

As argued by Bekaert and Mehl (2019), equity market integration is likely related to broader financial market integration and thus eligible to serve as a relevant capital openness measure to study the trilemma hypothesis. Fig. 2 indeed provides suggestive evidence with the close comovement of average capital flow restrictions in the equity and bond markets of the sample countries in the recent decades.

To test the trilemma hypothesis, we estimate variants of the following panel regression model for each currency regime:

$$
\Delta R_{i t}=\alpha_{0}+\alpha_{1} \Delta R_{i t}^{\text {base }}+\alpha_{2}\left(\Delta R_{i t}^{\text {base }} \times I N T_{i t}\right)+\alpha_{3} I N T_{i t}+\gamma Z_{i t-k}+u_{i t}
$$

where $\Delta R_{i t}$ is the change in country $i$ 's policy rate at time $t$, with a "base" superscript indicating the base country; $I N T_{i t}$ is an integration indicator $\left(=\hat{\beta}_{i, t}^{g l o}\right.$ from Eq. (1)); $\boldsymbol{Z}_{\boldsymbol{i t}-\boldsymbol{k}}$ is a vector of other control variables; and $u_{i t}$ is a random error term. ${ }^{4,5}$ Other variables include domestic conditions such as lagged RGDP growth $\left(\Delta Y_{i t-1}\right)$ and change in inflation rate $\left(\Delta \pi_{i t-1}\right)$, lagged policy rate $\left(R_{i t-1}\right)$, and contemporaneous percentage change in the VIX index $\left(\Delta V I X_{t}\right)$.

We would expect positive coefficients of growth and the inflation rate due to policy responses to fight against an overheated economy and the development of inflation, respectively. A negative sign for the lagged local policy rate would be associated with a stabilizing tendency for rate adjustments (Han and Wei, 2018). A positive coefficient for the VIX index would reflect

\footnotetext{
${ }^{4}$ Following Klein and Shambaugh (2015), a base country is Australia for New Zealand, Germany for much of Europe, Malaysia for Singapore, and the United States for the remaining sample countries. We make sure that local country $i$ does not include the United States.

${ }^{5}$ To mitigate the possible impact of outliers, we use $\ln (1+x)$ where $x=R, I N T$, which we refer to as $R$ and $I N T$ for ease of notation.
} 
a monetary policy response to avoid large capital flights or depreciation pressures during a period of elevated global financial uncertainty.

Using Eq. (2), interest rate pass-through is identified by the marginal effect of the base rate, $\alpha_{1}+\alpha_{2} I N T_{i t}$, with $\alpha_{2}$ capturing the impact of integration. Stronger pass-through will be interpreted as less monetary independence.

\subsection{Data}

Our data cover the period from $1995 \mathrm{q} 1$ to $2018 \mathrm{q} 4$ and include 19 AEs and 23 EMEs. ${ }^{6}$ The data for daily stock market indices and the U.S. 3-month T-bill yields are from Global Financial Data (GFD), and the information needed for calculating market capitalization are from the Datastream and CRSP databases. Central bank policy rates (or discount rates) are from BIS and the IMF's International Financial Statistics (IFS), supplemented by the money market rates available from the OECD and IFS. Exchange rate regime classifications are taken from Shambaugh (2004) and Obstfeld et al. (2010), whose annual observations are interpolated to a quarterly frequency via the constant-match average method. ${ }^{7}$ The information for RGDP and CPI inflation rates comes from the World Bank's General Economic Monitor, and the Chicago Board Options Exchange Volatility Index (VIX) from the St. Louis Fed's FRED.

\section{Empirical results}

Table 1 reports results based on a reduced-form specification of Eq. (2), ignoring the integration variable and its interaction term. Like in Shambaugh (2004), the estimations are

\footnotetext{
${ }^{6}$ The sample period is partly dictated by the availability of high-frequency financial variables for EMEs.

${ }^{7}$ Pegs refer to exchange rate changes within \pm 2 percent bands against the base currency, and soft pegs, up to \pm 5 percent bands. These two regimes are mutually exclusive. Floats refer to the rest of observations.
} 
performed across the four corners of the trilemma space. ${ }^{8}$ Reported standard errors are clustered at the country level.

Full sample estimates are presented in Panel A. Comparing the base rate coefficients in columns (1) and (3), we clearly see an effect of integration in the peg sample, with less integrated pegs showing a coefficient of 0.568 and $R^{2}$ of 0.191 , and more integrated pegs displaying a coefficient of 0.993 and $R^{2}$ of 0.808 . Thus, while financial market segmentation may afford some monetary independence under a peg, a deepening of financial integration noticeably restricts policy autonomy by significantly increasing interest rate pass-through.

Reviewing nonpeg results in columns (5) and (7), we find considerably smaller base rate coefficients and a smaller effect of integration, with a coefficient of 0.363 for less integrated and 0.444 for more integrated countries. The $R^{2}$ statistics are much lower than those of pegs, and their differences across integration stages are smaller as well. As shown in columns (2), (4), (6), and (8), the pass-through coefficients still follow the same pattern when controlling for the other variables, which exhibit the expected signs when statistically significant.

Panels $\mathrm{B}$ and $\mathrm{C}$ report results for AEs and EMEs, respectively. From the peg sample results, columns (1) and (3) of Panel B show virtually no differences in pass-through across integration stages in AEs, as suggested by $\alpha_{1}=0.97$ to 0.98 , implying a lack of autonomy and little effect of integration in the eurozone countries. Panel $\mathrm{C}$, however, shows a marked difference, with a coefficient of 0.204 (insignificant) for segmented and 1.142 for integrated countries, suggesting that pegging EMEs appear to lose policy autonomy when their financial markets are highly integrated. Unlike AEs, however, less integrated EMEs seem to keep their local policy rates decoupled from the international base rates.

\footnotetext{
${ }^{8}$ A country-quarter observation is classified as more integrated when the global beta estimate is greater than its sample median value and less integrated otherwise. Nonpegs include both soft pegs and floats.
} 
From the nonpeg sample results in Panel B, coefficients of 0.424 in column (5) and 0.653 in column (7) indicate that, while deviating from a hard peg provides partial autonomy in AEs, the higher degree of integration tends to strengthen the policy rate comovements and potentially undermine the autonomy more severely. The analogous results for EMEs are presented in Panel C. The lower values of the base rate coefficients imply that non-pegging EMEs generally better insulate their domestic policy rates from foreign monetary shocks than their AE counterparts. Additionally, the extent of integration does not appear to significantly alter their policy capacity. The corresponding $R^{2}$ statistics deliver the same message.

From the results in the even columns, we also find significant effects of changes in growth and inflation rates on local policy rates only in the nonpeg subsamples. This finding reflects the notion that monetary authorities without a currency peg commitment could direct policy rates to domestic objectives. It is also worth noting that the VIX variable has a significant impact only on EMEs' interest rates, particularly with non-pegging regimes.

Table 2 presents estimated coefficients of Eq. (2), which allows for an integration measure to be continuous. From the full sample results in Panel A, the significantly positive $\hat{\alpha}_{1}$ and $\hat{\alpha}_{2}$ in column (1) signify that the peggers' interest rate pass-through can increase considerably as their financial integration progresses. For example, given a $1 \%$ increase in the base rate, a one-standard-deviation increase in $I N T(=0.242)$ is expected to raise the passthrough by 0.25 percentage points more than otherwise. By contrast, the insignificant and small $\hat{\alpha}_{1}$ and $\hat{\alpha}_{2}$ reported in column (2) suggest that exchange rate flexibility enables a country to be isolated from base rate shocks regardless of the extent of integration.

The AEs sample results presented in columns (3) and (4) verify the findings in Table 1; the pegged interest rate moves almost one-to-one with the base rate, irrespective of the degree of 
financial integration. Relaxing exchange rate fixity offers some buffer to base rate shocks, but increasing financial integration could place restrictions on policy independence.

According to the EMEs sample results in column (5), the pegged interest rate can be independently managed in a segmented market, but a deepening of market integration can damage a country's policy discretion substantially, as implied by $\alpha_{2}=1.495$. In addition, unlike AEs, non-pegging EMEs can keep their policy rates disconnected from the foreign rates no matter how strongly their markets are integrated, as demonstrated by the results in column (6).

The patterns observed in Panel A of Table 2 are robust to the inclusion of additional control variables, as shown in Panel B. ${ }^{9}$

As our last exercise, we consider a finer gradation of currency regimes so that each country group is divided into pegs, soft pegs, and floats while allowing for a full range of integration. Fig. 3 illustrates the marginal effect of the base rate (with thick solid lines) along with the $90 \%$ confidence interval (dashed lines) for AEs in Panel A and EMEs in Panel B. ${ }^{10}$ The estimated slope coefficient $\alpha_{2}$ and its robust standard error, $t$ statistic, and sample size are also reported in each plot. ${ }^{11}$

From the plots in the first row, we see that there is strong interest rate pass-through in pegging AEs, with the degree of integration having an insignificant effect. However, pegging EMEs can independently manage their policy interest rates until the market integration reaches 0.13 , which is about the $29^{\text {th }}$ percentile in the pegging EMEs subsample. Beyond that point,

\footnotetext{
${ }^{9}$ The core results hold when using the alternative exchange rate regime of Ilzetzki et al. (2019), bootstrap standard errors, or long-term government bond yields, and when dropping the country-quarter observations associated with zero-lower-bound episodes (results available upon request).

${ }^{10}$ The confidence intervals are calculated based on the standard error for the marginal effect of the base rate in Eq. (2), $\sqrt{\operatorname{var}\left(\alpha_{1}\right)+I N T^{2} \operatorname{var}\left(\alpha_{2}\right)+2 \operatorname{cov}\left(\alpha_{1}, \alpha_{2}\right) I N T}$.

${ }^{11}$ These results are based on the estimation of Eq. (2) without other variables in $\boldsymbol{Z}$, but including them does not change the conclusion.
} 
integration starts limiting policy autonomy in a statistically significant and linear manner, suggesting that a high level of market segmentation is necessary for autonomy in pegging EMEs.

Soft peg results are presented in the second row. Allowing slightly larger exchange rate fluctuations with up to \pm 5 percent bands does not offer much buffer against base rate shocks in AEs. By contrast, it does afford considerable autonomy in EMEs at almost all integration levels, corroborating the finding in Klein and Shambaugh (2015). In both country groups, however, the extent of market integration itself does not significantly alter monetary policy spillovers, as indicated by insignificant slope coefficients.

Finally, as shown in the plots in the last row, while floats provide monetary freedom to EMEs regardless of their level of financial integration, AEs may start losing their monetary controls as their integration levels rise above 0.15 , which corresponds to about the $12^{\text {th }}$ percentile in the floating AEs subsample. In other words, the integration effect of limiting autonomy in AEs is so large that a floating exchange rate regime alone cannot guarantee monetary independence.

\section{Conclusion}

This paper re-examines the validity of the open-economy trilemma hypothesis in the recent period of globalization using de facto financial market integration estimated based on an international CAPM. Our results suggest that EMEs' policy constraints are closely in line with the trilemma predictions. Conversely, AEs' policy rates are not completely independent of the base rates even under a floating exchange rate regime due to their tight financial market integration, yielding some support for the dilemma hypothesis. 


\section{References}

Aizenman, J., Chinn, M.D. Ito, H., 2016. Monetary policy spillovers and the trilemma in the new normal: Periphery country sensitivity to core country conditions. Journal of International Money and Finance, 68, 298-330.

Bekaert, G., Hodrick, R., Zhang, X., 2009. International stock return comovements. Journal of Finance 64, 2591-2626.

Bekaert, G., Mehl, A., 2019. On the global financial market integration "swoosh" and the trilemma. Journal of International Money and Finance 94, 227-245.

Fernández, A., Klein, M.W., Rebucci, A., Schindler, M., Uribe, M., 2016. Capital control measures: A new dataset. IMF Economic Review 64, 548-574.

Frankel, J., Schmukler, S.L., Serven, L., 2004. Global transmission of interest rates: Monetary independence and currency regime. Journal of International Money and Finance 23, 701-733.

Han, X., Wei, S-J., 2018. International transmissions of monetary shocks: Between a trilemma and a dilemma. Journal of International Economics 110, 205-219.

Ilzetzki, E., Reinhart, C., Rogoff, K., 2019. Exchange arrangements entering the twenty-first century: Which anchor will hold? Quarterly Journal of Economics 134, 599-646.

Klein, M.W., Shambaugh, J.C., 2015. Rounding the corners of the policy trilemma: Sources of monetary policy autonomy. American Economic Journal: Macroeconomics 7, 33-66.

Mundell, R., 1963. Capital mobility and stabilization policy under fixed and flexible exchange rates. Canadian Journal of Economics and Political Science 29, 475-485.

Obstfeld, M., Shambaugh, J.C., Taylor, A.M., 2005. The trilemma in history: Tradeoffs among exchange rates, monetary policies, and capital mobility. Review of Economics and Statistics $87,423-438$.

Obstfeld, M., Shambaugh, J.C., Taylor, A.M., 2010. Financial stability, the trilemma, and international reserves. American Economic Journal: Macroeconomics 2, 57-94.

Rey, H., 2015. Dilemma not trilemma: The global financial cycle and monetary policy independence. NBER Working Paper No. 21162.

Shambaugh, J.C., 2004. The effect of fixed exchange rates on monetary policy. Quarterly Journal of Economics 119, 301-352. 


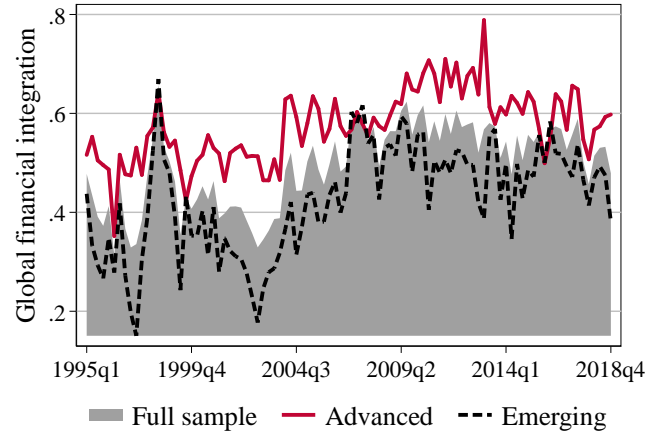

Fig. 1. Global financial integration across samples. (Data source: GFD, Datastream, and CRSP)
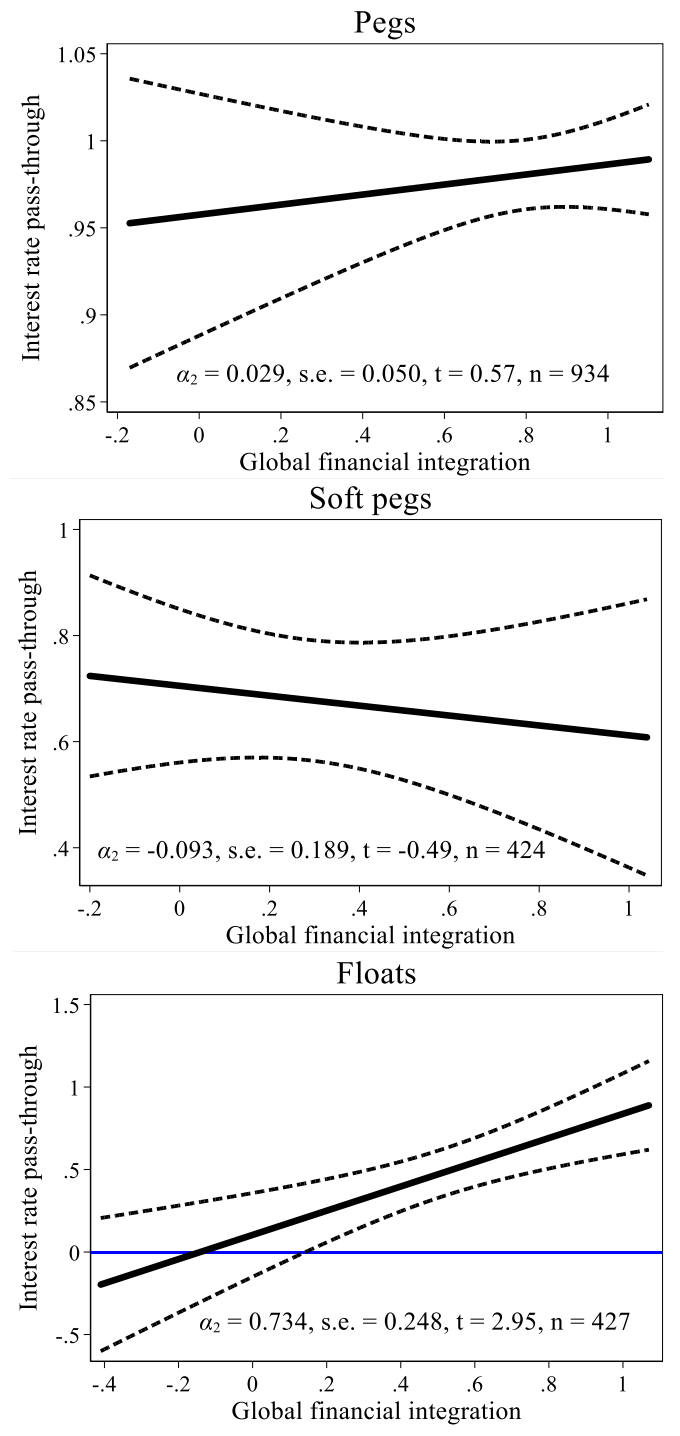

A. Advanced economies

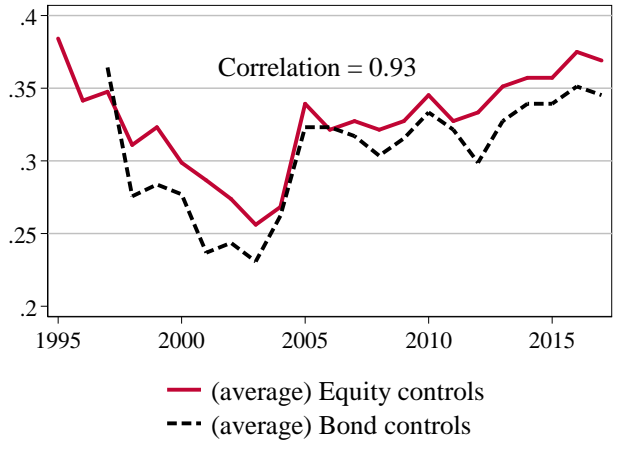

Fig. 2. Equity and bond flow restrictions in the sample. (Data source: Fernández et al., 2016)
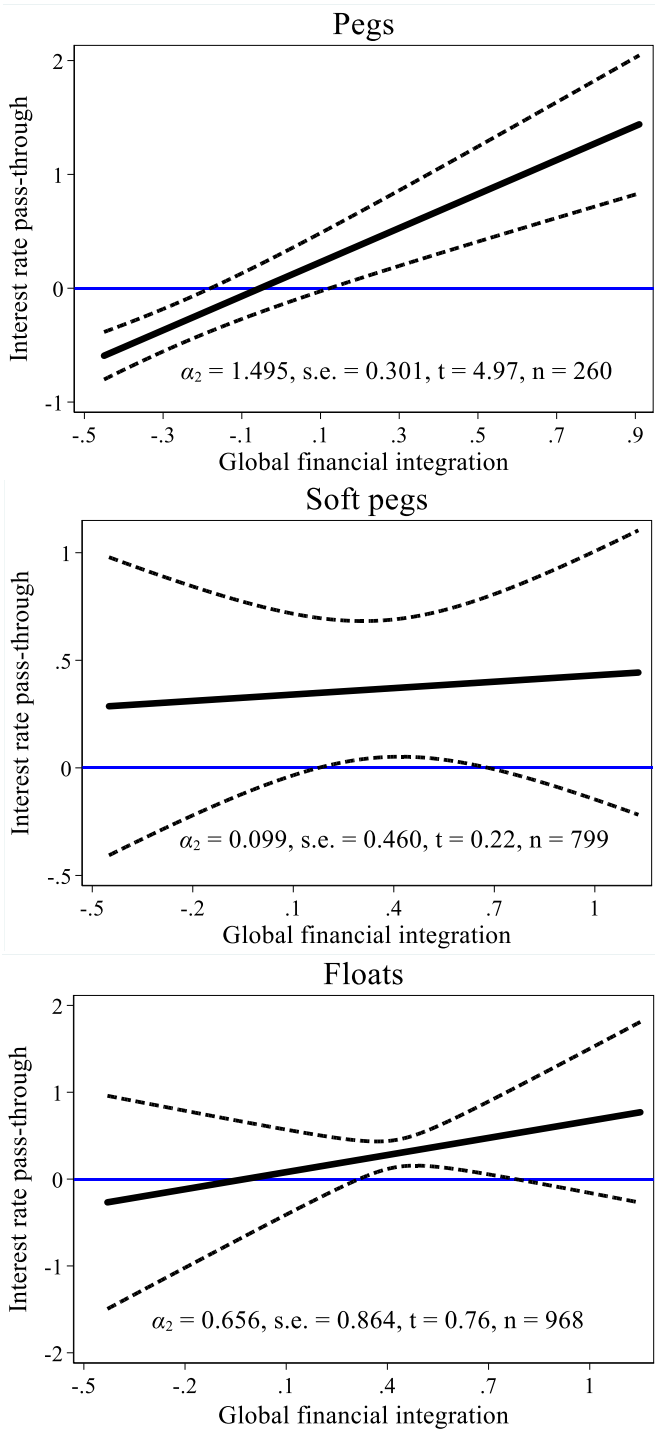

B. Emerging markets

Fig. 3. Interest rate pass-through and global financial integration. Dashed lines indicate the $90 \%$ confidence interval. 
Table 1

Interest rate pass-through: evidence from subsample regressions.

\begin{tabular}{|c|c|c|c|c|c|c|c|c|}
\hline \multirow[b]{3}{*}{ Variable } & \multicolumn{4}{|c|}{ Pegs } & \multicolumn{4}{|c|}{ Nonpegs } \\
\hline & \multicolumn{2}{|c|}{ Less Integrated } & \multicolumn{2}{|c|}{ More Integrated } & \multicolumn{2}{|c|}{ Less Integrated } & \multicolumn{2}{|c|}{ More Integrated } \\
\hline & $(1)$ & $(2)$ & (3) & (4) & (5) & (6) & (7) & (8) \\
\hline & \multicolumn{8}{|c|}{ A. Full sample } \\
\hline$\Delta R_{i t}^{\text {base }}$ & $\begin{array}{c}0.568 * * * \\
(0.171)\end{array}$ & $\begin{array}{c}0.554 * * * \\
(0.175)\end{array}$ & $\begin{array}{c}0.993 * * * \\
(0.024)\end{array}$ & $\begin{array}{c}0.976 * * * \\
(0.031)\end{array}$ & $\begin{array}{c}0.363 * * * \\
(0.115)\end{array}$ & $\begin{array}{c}0.267 * * \\
(0.108)\end{array}$ & $\begin{array}{c}0.444 * * * \\
(0.135)\end{array}$ & $\begin{array}{c}0.313^{* *} \\
(0.139)\end{array}$ \\
\hline \multirow[t]{2}{*}{$\Delta Y_{i t-1}$} & & -0.006 & & -0.001 & & $0.025^{* *}$ & & 0.010 \\
\hline & & $(0.008)$ & & $(0.001)$ & & $(0.011)$ & & $(0.042)$ \\
\hline \multirow[t]{2}{*}{$\Delta \pi_{i t-1}$} & & 0.036 & & 0.021 & & -0.025 & & $0.033 * * *$ \\
\hline & & $(0.027)$ & & $(0.015)$ & & $(0.100)$ & & $(0.008)$ \\
\hline \multirow[t]{2}{*}{$R_{i t-1}$} & & $-0.027 * *$ & & $-0.020 * *$ & & $-0.073 * * *$ & & $-0.059 * * *$ \\
\hline & & $(0.011)$ & & $(0.007)$ & & $(0.010)$ & & $(0.012)$ \\
\hline \multirow{2}{*}{$\Delta V I X_{t}$} & & 0.0001 & & -0.0001 & & $0.001^{\dagger}$ & & $0.002 * * *$ \\
\hline & & $(0.0002)$ & & $(0.0002)$ & & $(0.001)$ & & $(0.001)$ \\
\hline Obs. & 444 & 440 & 750 & 748 & 1,445 & 1,427 & 1,173 & 1,171 \\
\hline \multirow[t]{2}{*}{$R^{2}$} & 0.191 & 0.240 & 0.808 & 0.819 & 0.007 & 0.154 & 0.005 & 0.110 \\
\hline & \multicolumn{8}{|c|}{ B. Advanced economies } \\
\hline \multirow[t]{2}{*}{$\Delta R_{i t}^{\text {base }}$} & $0.973 * * *$ & $0.920 * * *$ & $0.976^{* * *}$ & $0.962 * * *$ & $0.424 * * *$ & $0.387 * * *$ & $0.653 * * *$ & $0.552 * * *$ \\
\hline & $(0.022)$ & $(0.033)$ & $(0.015)$ & $(0.022)$ & $(0.132)$ & $(0.123)$ & $(0.086)$ & $(0.100)$ \\
\hline \multirow[t]{2}{*}{$\Delta Y_{i t-1}$} & & 0.001 & & -0.002 & & $0.018^{* *}$ & & $0.035 * *$ \\
\hline & & $(0.003)$ & & $(0.001)$ & & $(0.008)$ & & $(0.013)$ \\
\hline \multirow[t]{2}{*}{$\Delta \pi_{i t-1}$} & & $0.042^{\dagger}$ & & 0.016 & & 0.010 & & $0.150 * * *$ \\
\hline & & $(0.025)$ & & $(0.012)$ & & $(0.030)$ & & $(0.042)$ \\
\hline \multirow[t]{2}{*}{$R_{i t-1}$} & & $-0.036 * * *$ & & $-0.020 * *$ & & $-0.021 * * *$ & & -0.009 \\
\hline & & $(0.011)$ & & $(0.007)$ & & $(0.005)$ & & $(0.007)$ \\
\hline \multirow[t]{2}{*}{$\Delta V I X_{t}$} & & 0.0002 & & $5 \times 10^{-5}$ & & -0.0004 & & -0.0003 \\
\hline & & $(0.0003)$ & & $(0.0001)$ & & $(0.001)$ & & $(0.0003)$ \\
\hline Obs. & 221 & 217 & 713 & 711 & 384 & 383 & 467 & 465 \\
\hline \multirow[t]{2}{*}{$R^{2}$} & 0.788 & 0.823 & 0.851 & 0.861 & 0.151 & 0.181 & 0.295 & 0.379 \\
\hline & \multicolumn{8}{|c|}{ C. Emerging markets } \\
\hline \multirow{2}{*}{$\Delta R_{i t}^{\text {base }}$} & 0.204 & 0.211 & $1.142 * * *$ & $1.040 * * *$ & $0.342 * *$ & $0.241^{\dagger}$ & $0.333^{\dagger}$ & 0.180 \\
\hline & $(0.203)$ & $(0.204)$ & $(0.117)$ & $(0.148)$ & $(0.149)$ & $(0.141)$ & $(0.206)$ & $(0.192)$ \\
\hline \multirow[t]{2}{*}{$\Delta Y_{i t-1}$} & & -0.012 & & -0.002 & & $0.022^{\dagger}$ & & -0.002 \\
\hline & & $(0.009)$ & & $(0.010)$ & & $(0.014)$ & & $(0.049)$ \\
\hline$\Delta \pi_{i t-1}$ & & 0.028 & & 0.091 & & -0.029 & & $0.033 * * *$ \\
\hline & & $(0.032)$ & & $(0.065)$ & & $(0.103)$ & & $(0.008)$ \\
\hline$R_{i t-1}$ & & $-0.029^{*}$ & & -0.0003 & & $-0.076 * * *$ & & $-0.067 * * *$ \\
\hline & & $(0.014)$ & & $(0.049)$ & & $(0.011)$ & & $(0.014)$ \\
\hline$\Delta V I X_{t}$ & & -0.0001 & & $-0.003 * *$ & & $0.002 *$ & & $0.003 * * *$ \\
\hline & & $(0.0002)$ & & $(0.001)$ & & $(0.001)$ & & $(0.001)$ \\
\hline Obs. & 223 & 223 & 37 & 37 & 1,061 & 1,044 & 706 & 706 \\
\hline$R^{2}$ & 0.020 & 0.093 & 0.598 & 0.683 & 0.005 & 0.156 & 0.002 & 0.114 \\
\hline
\end{tabular}

Notes: The dependent variable is $\Delta R_{i t}$, which represents the quarterly changes in country $i$ 's policy rate at time $t$. Robust standard errors reported in parentheses are clustered at the country level. $* * *, * *, *$ and ${ }^{\dagger}$ indicate statistical significance at the $1 \%, 5 \%, 10 \%$ and $15 \%$ levels, respectively. 
Table 2

Interest rate pass-through: evidence from interaction regressions.

\begin{tabular}{|c|c|c|c|c|c|c|}
\hline \multirow[b]{2}{*}{ Variable } & \multicolumn{2}{|c|}{ Full sample } & \multicolumn{2}{|c|}{ Advanced economies } & \multicolumn{2}{|c|}{ Emerging markets } \\
\hline & $\begin{array}{l}\text { Pegs } \\
(1)\end{array}$ & $\begin{array}{c}\text { Nonpegs } \\
\text { (2) }\end{array}$ & $\begin{array}{l}\text { Pegs } \\
(3)\end{array}$ & $\begin{array}{c}\text { Nonpegs } \\
\text { (4) }\end{array}$ & $\begin{array}{c}\text { Pegs } \\
(5)\end{array}$ & $\begin{array}{c}\text { Nonpegs } \\
(6)\end{array}$ \\
\hline & \multicolumn{6}{|c|}{ A. With no other controls } \\
\hline \multirow[t]{2}{*}{$\Delta R_{i t}^{\text {base }}$} & $0.309^{*}$ & 0.227 & $0.958 * * *$ & 0.287 & 0.080 & 0.218 \\
\hline & $(0.176)$ & $(0.216)$ & $(0.042)$ & $(0.193)$ & $(0.136)$ & $(0.270)$ \\
\hline \multirow{2}{*}{$\Delta R_{i t}^{\text {base }} \times I N T_{i t}$} & $1.017 * * *$ & 0.365 & 0.029 & $0.488^{*}$ & $1.495 * * *$ & 0.272 \\
\hline & $(0.237)$ & $(0.468)$ & $(0.050)$ & $(0.270)$ & $(0.301)$ & $(0.637)$ \\
\hline \multirow[t]{2}{*}{$I N T_{i t}$} & $0.0003^{* *}$ & 0.0004 & $0.0002^{\dagger}$ & $4.56 \times 10^{-5}$ & 0.0003 & 0.0004 \\
\hline & $(0.0002)$ & $(0.001)$ & $(0.0001)$ & $(0.0001)$ & $(0.0003)$ & $(0.001)$ \\
\hline Obs. & 1,194 & 2,618 & 934 & 851 & 260 & 1,767 \\
\hline \multirow[t]{2}{*}{$R^{2}$} & 0.560 & 0.007 & 0.837 & 0.236 & 0.168 & 0.003 \\
\hline & \multicolumn{6}{|c|}{ B. With additional controls } \\
\hline \multirow[t]{2}{*}{$\Delta R_{i t}^{\text {base }}$} & $0.308^{*}$ & 0.223 & $0.944 * * *$ & 0.239 & 0.100 & 0.236 \\
\hline & $(0.178)$ & $(0.155)$ & $(0.048)$ & $(0.181)$ & $(0.142)$ & $(0.192)$ \\
\hline \multirow{2}{*}{$\Delta R_{i t}^{\text {base }} \times I N T_{i t}$} & $0.989 * * *$ & 0.127 & 0.017 & $0.441^{\dagger}$ & $1.435^{* * *}$ & -0.049 \\
\hline & $(0.232)$ & $(0.318)$ & $(0.052)$ & $(0.274)$ & $(0.315)$ & $(0.424)$ \\
\hline \multirow[t]{2}{*}{$I N T_{i t}$} & -0.0002 & 0.0003 & $-4.81 \times 10^{-5}$ & $4.72 \times 10^{-6}$ & -0.0003 & 0.001 \\
\hline & $(0.0002)$ & $(0.001)$ & $(0.0002)$ & $(0.0001)$ & $(0.0005)$ & $(0.001)$ \\
\hline \multirow[t]{2}{*}{$\Delta Y_{i t-1}$} & -0.004 & 0.021 & -0.001 & $0.027 * * *$ & -0.011 & 0.015 \\
\hline & $(0.003)$ & $(0.020)$ & $(0.001)$ & $(0.009)$ & $(0.008)$ & $(0.023)$ \\
\hline \multirow[t]{2}{*}{$\Delta \pi_{i t-1}$} & $0.033 * *$ & $0.030^{* * *}$ & $0.020^{*}$ & $0.077^{* *}$ & $0.042^{\dagger}$ & $0.029^{* * *}$ \\
\hline & $(0.015)$ & $(0.008)$ & $(0.010)$ & $(0.029)$ & $(0.025)$ & $(0.008)$ \\
\hline \multirow[t]{2}{*}{$R_{i t-1}$} & $-0.026^{* * *}$ & $-0.064 * * *$ & $-0.024 * * *$ & $-0.018 * * *$ & $-0.028^{*}$ & $-0.070 * * *$ \\
\hline & $(0.008)$ & $(0.009)$ & $(0.007)$ & $(0.003)$ & $(0.016)$ & $(0.011)$ \\
\hline \multirow[t]{2}{*}{$\Delta V I X_{t}$} & -0.0001 & $0.001 * * *$ & 0.0001 & -0.0002 & $-0.001^{*}$ & $0.002 * * *$ \\
\hline & $(0.0001)$ & $(0.001)$ & $(0.0001)$ & $(0.0003)$ & $(0.0003)$ & $(0.001)$ \\
\hline Obs. & 1,188 & 2,598 & 928 & 848 & 260 & 1,750 \\
\hline$R^{2}$ & 0.586 & 0.123 & 0.851 & 0.283 & 0.235 & 0.125 \\
\hline
\end{tabular}

Notes: The dependent variable is $\Delta R_{i t}$, which represents the quarterly changes in country $i$ 's policy rate at time $t$. Robust standard errors reported in parentheses are clustered at the country level. $* * *, * * *$ and ${ }^{\dagger}$ indicate statistical significance at the $1 \%, 5 \%, 10 \%$ and $15 \%$ levels, respectively. 